SISTEMA
ELETRONIICO
DE REVISTAS
SER I UfPR

\title{
Mudanças espaço temporal da disponibilidade de serviços ecossistêmicos em uma microbacia hidrográfica do nordeste brasileiro
}

\section{Spatial and temporal changes of the ecosystem services availability in a microwatershed in Northeast Brazil}

Lucianna Marques Rocha FERREIRA ${ }^{1 *}$, Luciana Slomp ESTEVES ${ }^{2}$, Enio Pereira de SOUZA ${ }^{1}$, Carlos Antonio Costa dos SANTOS ${ }^{1}$, Veneziano Guedes de Sousa REGO ${ }^{3}$

${ }^{1}$ Universidade Federal de Campina Grande (UFCG), Campina Grande, PB, Brasil.

${ }^{2}$ Bournemouth University, United Kingdom.

${ }^{3}$ Universidade Federal de Campina Grande (UFCG), Patos, PB, Brasil

*E-mail de contato: lucianna.mrf@gmail.com

Artigo recebido em 4 de fevereiro de 2018, versão final aceita em 14 de outubro de 2019.

RESUMO: $\quad$ A mudança no uso e ocupação da terra altera a dinâmica de ecossistemas e afeta a provisão de serviços ecossistêmicos, que são a base para a manutenção da vida e do bem-estar físico, mental e espiritual humano. Nesse contexto, o estabelecimento humano em países em desenvolvimento ocorreu, de modo geral, de forma desordenada e sem planejamento, ocasionando deterioração ambiental. No nordeste brasileiro, onde o recurso hídrico é escasso, as aglomerações humanas tendem a ocorrer próximas à rede hídrica, elevando a pressão antrópica sobre esse recurso. Este trabalho analisa as alterações na provisão de serviços ecossistêmicos na Microbacia Hidrográfica Riacho das Piabas, Paraíba, Brasil, associadas a mudanças do uso e ocupação da terra entre os anos de 1989, 2007 e 2014. Mudanças no uso e ocupação da terra foram identificadas e quantificadas por meio de técnicas de sensoriamento remoto e sistema de informação geográfica. Os serviços ecossistêmicos foram analisados por meio de média de valor monetário estimado de serviço ecossistêmico (VSE) disponível na literatura, utilizando o método de transferência de benefício. Em 1989, o valor total de serviço ecossistêmico foi estimado em US\$ 7,18 milhões, reduzindo para US\$ 3,73 milhões em 2007 e US\$ 2,72 milhões em 2014. Houve aumento de $115 \%$ de área construída entre 1989 e 2014, resultando em redução de serviços ecossistêmicos de 62\% entre os anos de 1989 e 2014. O declínio do VSE reflete o impacto negativo do processo de urbanização na manutenção de serviços ecossistêmicos, sobretudo os ofertados pela vegetação. A categoria vegetação arbórea foi a mais valiosa para a área de estudo, disponibilizando maior número de funções ecossistêmicas com alto VSE. Entretanto, foi a categoria que mais perdeu área ao longo 
dos anos. Portanto, é fundamental planejar, criar e manter áreas verdes para minorar os impactos do processo de urbanização na provisão de serviços ecossistêmicos.

Palavras-chave: expansão urbana; mudança da paisagem; recursos naturais; valoração de serviços ecossistêmicos; espaço verde.

ABSTRACT: Changes in land use and land cover (LULC) alters the dynamics of ecosystems and the provision of ecosystem services, which are essential to the maintenance of life and human well-being. Human settlement in developing countries generally occurs in a disorderly and unplanned manner, leading to environmental degradation. In Northeast Brazil, water is a scarce resource and urbanization tends to occur along the water network and increase pressure on the quality and availability of this resource. This paper analyzes LULC changes in 1989, 2007 and 2014 and the associated impacts on the provision of ecosystem services in the microwatershed Riacho das Piabas (Paraíba, Brazil). LULC changes were identified and quantified using remote sensing techniques and geographic information system. Ecosystem services value (ESV) were estimated using average monetary value available in the literature using the benefit transfer method. In 1989 the estimated total ESV was US\$ 7.18 million, reducing to US\$ 3.73 million in 2007 and US\$2.72 million in 2014. There was a 115\% increase of built area between 1989 and 2014 that resulted in reduction of ecosystem services of $62 \%$ between 1989 and 2014. The decline in ESV reflects the negative impact of the urbanization process on the provision of ecosystem services, especially those offered by vegetation. The arboreal vegetation was the most valuable LULC class in the study area, and the one that showed the greatest reduction in area. Planning, creating and maintaining green areas is critical to mitigate the impacts of urbanization on the provision of ecosystem services.

Keywords: urban expansion; landscape change; natural resources; ecosystem services valuation; green space.

\section{Introdução}

A natureza proporciona bens e serviços que, direta ou indiretamente, são úteis para os seres humanos e para a manutenção da vida no planeta (ex.: água potável, alimentos, conforto térmico, entre outros) (MEA, 2005; La Notte et al., 2017), sendo a base para o desenvolvimento socioeconômico (Hails \& Ormerod, 2013; Costanza et al., 2014). Em contrapartida, a deterioração do ambiente pela ação antrópica tem indisponibilizado o acesso a certos bens e serviços ecossistêmicos (MEA, 2005; Tolessa et al., 2017). Estima-se que cerca de 60\% dos bens e serviços ecossistêmicos essenciais para a manutenção do bem-estar humano apresentam algum grau de deterioração (MEA, 2005).
Neste contexto, o processo de expansão urbana é considerado um dos principais fatores de mudança do uso da terra no âmbito global (Elmqvist et al., 2013) e, consequentemente, de redução de serviços ecossistêmicos (Robinson et al., 2013). Entre 2000 e 2030 as áreas urbanas irão expandir em torno de $200 \%$ e aproximadamente 5 bilhões de pessoas viverão nas cidades (Fragkias et al., 2013). A concentração populacional em cidades aumenta a demanda de bens e de serviços ecossistêmicos (Solecki et al., 2013), de maneira que as áreas urbanas ficam constantemente dependentes de sistemas ecológicos de áreas rurais (Hails \& Ormerod, 2013). Os atuais desafios, na temática de sistemas urbanos, estão relacionados a capacidade de antever padrões estruturais e funcionais de ecossistemas modificados 
pelo processo de expansão urbana e a evolução da percepção humana como ser consciente e indissociável do ecossistema (Groffman et al., 2017).

A identificação e a valoração de bens e de serviços ecossistêmicos, mesmo não sendo medida de forma absoluta e exata, tem sido utilizada para entender os ganhos e as perdas resultantes das mudanças no uso e na ocupação da terra (de Groot et al., 2012; Mendoza-González et al., 2012; Tolessa et al., 2017; Yi et al., 2017), tendo aplicação prática para desenvolvimento de políticas públicas, identificação de áreas vulneráveis em que há serviços de ecossistemas sensíveis à alteração ambiental, bem como corrobora processos de Educação Ambiental e de sensibilização de cidadãos (de Groot et al., 2012; Baker et al., 2013; Green et al., 2016; Tolessa et al., 2017).

Diante do exposto, objetivou-se avaliar a alteração na disponibilidade de bens e de serviços ecossistêmicos associados à mudança do uso e ocupação da terra entre os anos de 1989, 2007 e 2014 na Microbacia Hidrográfica Riacho das Piabas- MBHRP (Paraíba, Brasil) e indicar estratégias de manejo de ecossistema em áreas em processo de urbanização.

\section{Material e métodos}

\section{1. Área de estudo}

A MBHRP encontra-se inserida na Bacia Hidrográfica do Rio Paraíba, na Região do médio Paraíba e Subbacia do Bodocongó, correspondendo à mesorregião do Agreste Paraibano e à microrregião de Campina Grande, Paraíba, Brasil (AESA, 2010). O limite geográfico da MBHRP abrange área de transição do bioma Mata Atlântica e Caatinga, ocorrendo tensão ecológica entre a vegetação Ombrófila Aberta e Savana Estépica, com predomínio de plantas caducifólias e presença de flora xerófita (IBGE, 2004). A MBHRP possui área de 3.541,14 hectares (ha) estendendo por três municípios paraibanos (Figura 1): Puxinanã (4,57\% do território da MBHRP), Lagoa Seca (6,47\% do território da MBHRP) e Campina Grande com $88,15 \%$ do território da MBHRP.

A capacidade de uso da terra é marcada por terras não cultiváveis, com limitações para culturas permanentes e terras íngremes susceptíveis à erosão (AESA, 2010). A geomorfologia na região é caracterizada pelo Planalto da Borborema com formas tabulares e convexas e os tipos de solos predominantes são planossolo (para o trecho médio e jusante) e neossolo nas cabeceiras (Santos et al., 2013).

De acordo com a classificação de Köppen-Geiger, o clima da região é As', quente e úmido, com estação seca no verão (Kootek et al., 2006). Entre os anos de 1993 e 2014, a temperatura máxima média anual foi $29^{\circ} \mathrm{C}$ e a temperatura mínima foi $23^{\circ} \mathrm{C}$ (INMET, 2015). A precipitação pluviométrica anual é em torno de $800 \mathrm{~mm}$ e o período do ano em que ocorre maior precipitação pluviométrica corresponde, normalmente, aos meses de março a junho (Macedo et al., 2011). A umidade relativa do ar é de aproximadamente 74\% (INMET, 2015).

No Nordeste brasileiro a ocupação humana aconteceu inicialmente sem planejamento, de forma desordenada e sem considerar os impactos negativos de ações humanas na dinâmica ecológica local (Evangelista, 2010). Essa realidade é observada na área da MBHRP, onde os bens ecossistêmicos disponíveis nessa região, como água potável e pastagem para os cavalos, foram atrativos para os "Tropeiros 
da Borborema" (viajantes tradicionais da região), que acabaram ocupando a área e dando origem a cidade de Campina Grande. Em um trecho nas antigas margens do Riacho das Piabas foi criado o Açude Velho, hoje um dos cartões postais da cidade e patrimônio histórico (Câmara, 1999).
Atualmente, o segmento médio e jusante da MBHRP é urbanizado e/ou canalizado, com moradias irregulares nas Áreas de Preservação Permanentes e em conflito com a legislação brasileira - Lei $\mathrm{n}^{\circ}$ 9.433, de 8 de janeiro de 1997 (Brasil, 1997) e Lei $\mathrm{n}^{\circ}$ 12.651, de 25 de maio de 2012 (Brasil,

\section{Legenda}

$\square$ América do Sul
$\square$ Brasil
$\square$ Paraíba
$\square$ MBHRP
$\square$ Municípios
$\square$ Rede de drenagem
$\square$ Área urbana
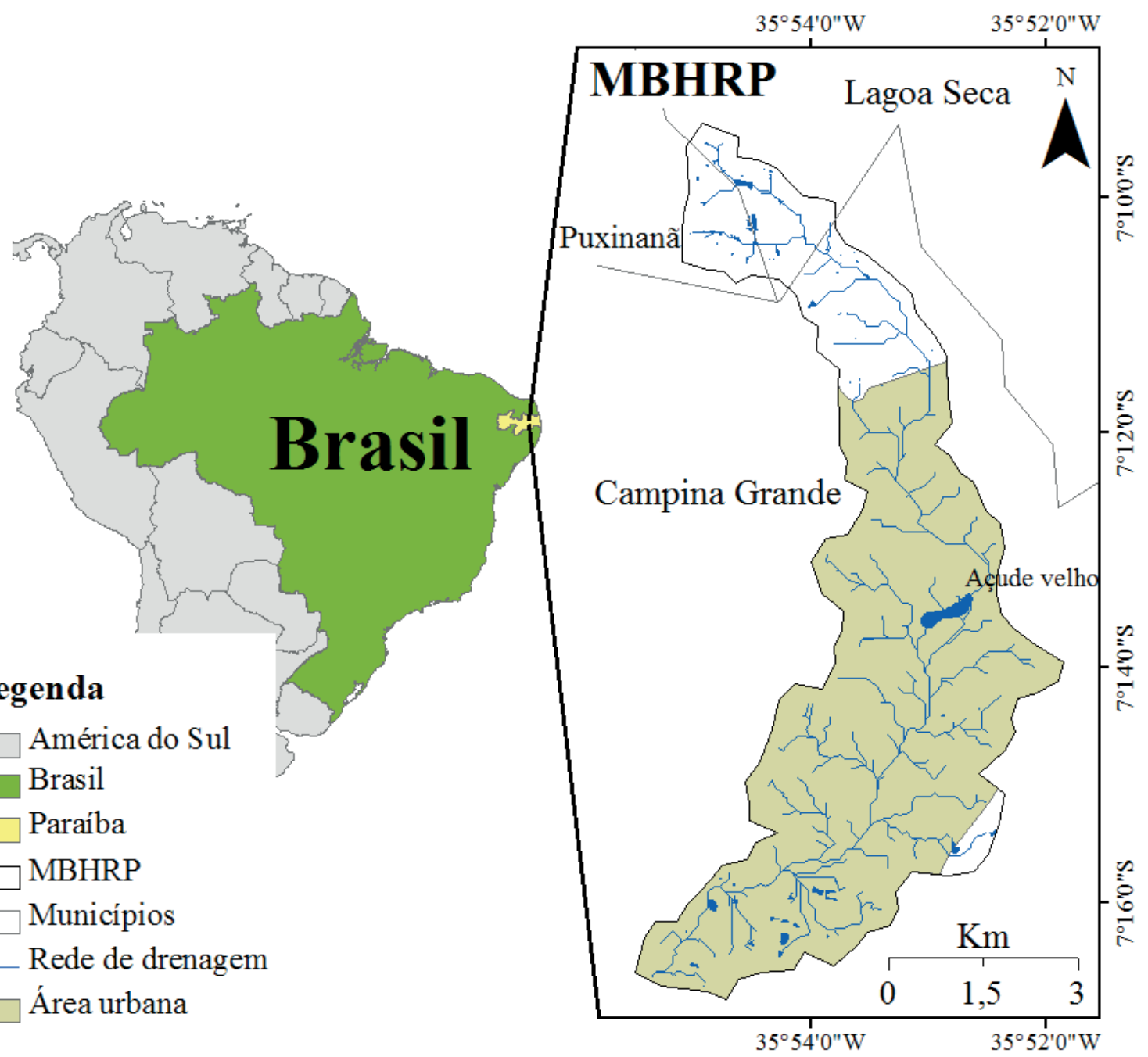

FIGURA 1 - Localização da Microbacia Hidrográfica Riacho das Piabas (Paraíba, Brasil). 
2012). Ademais, verifica-se trechos com ausência de saneamento ambiental e rede hídrica principal poluída. Do sistema hídrico, apenas a sua porção montante detém modo de vida rural, porém, com dinâmica ecológica alterada pelas ações antropogênicas negativas, como: construção de barragens ilegais de pequeno porte em propriedades privadas, segmentos sem vegetação ripária e com desenvolvimento de atividade agrícola e pastoril intensivas e desassistidas tecnicamente.

\subsection{Classificação do uso e ocupação da terra}

Os mapas temáticos do uso e ocupação da terra da MBHRP referentes aos anos de 1989, 2007 e 2014 foram obtidos por meio de classificação semi-supervisionada de imagens capturadas pelo sensor TM (Thematic Mapper) instalado no satélite Landsat 5 (Land Remote Sensing Satellite) e pelo sensor OLI (Operational Land Imager) a bordo do satélite Landsat 8 (Tabela 1). Sendo assim, realizou-se as seguintes etapas para gerar os mapas temáticos: georreferenciamento; processamento digital das imagens; classificação temática; e aferição da acurácia dos mapas.

As imagens de satélite foram adquiridas no site oficial da United States Geological Survey (USGS) Global Visualization Viewer (USGS, 2014). As imagens com menor cobertura de nuvens capturadas em dias que precederam eventos de precipitação foram selecionadas (Tabela 1). Este critério de seleção é imprescindível, uma vez que na MBHRP há predomínio de espécies de plantas caducifólias que perdem suas folhas no período de estiagem e que voltam a brotar após poucos dias de precipitação pluviométrica, alterando a resposta espectral.

O processamento digital de imagens de satélite e os mapas temáticos foram obtidos a partir do programa QGIS versão 3.4.11. As imagens de satélite foram georreferenciadas para UTM WGS 84, Zona 25, Sul (Código European Petroleum Survey Group: 32725), bem como foram submetidas a correção atmosférica. A posteriori, as imagens de 1989 e de 2007 foram registradas a partir da imagem de referência Landsat 8 , visto já ser ortorretificada e registrada.

Aplicou-se método de máxima verossimilhança como algoritmo classificador e a classificação digital semi-supervisionada foi baseada na composição de bandas espectrais 5,4 e 3 e 4, 3 e 2 para as imagens de 1989 e de 2007 capturas pelo sensor TM a bordo do satélite Landsat 5 e na composição de bandas espectrais 6, 5 e 4 e 5, 4 e 3 para imagem de 2014 capturada pelo sensor OLI a bordo do satélite Landsat 8. Adicionalmente, observou-se durante a classificação semi-supervisionada do uso e ocupação da terra

TABELA 1- Informações sobre as imagens orbitais utilizadas neste estudo.

\begin{tabular}{|c|c|c|c|}
\hline $\begin{array}{c}\text { Data da passagem do } \\
\text { satélite }\end{array}$ & Órbita/Ponto & Satélite/Sensor & Resolução radiométrica/Espacial \\
\hline $10 / 07 / 1989$ & $214 / 65$ & Landsat 5/TM & 8 bits $/ 30 \mathrm{~m}$ (bandas $1,2,3,4,5$, e 7 ) e $120 \mathrm{~m}$ (banda 6 ) \\
\hline $26 / 04 / 2014$ & $214 / 65$ & $\begin{array}{l}\text { Landsat 8/OLI e } \\
\text { TIRS }\end{array}$ & $\begin{array}{l}16 \text { bits } / 15 \mathrm{~m} \text { (banda } 8), 30 \mathrm{~m} \text { (bandas } 1,2,3,4,5,6,7 \text { e } 9) \mathrm{e} \\
100 \mathrm{~m} \text { (bandas } 10 \text { e } 11)\end{array}$ \\
\hline
\end{tabular}

FONTE: USGS (2014). 
o Índice de Vegetação por Diferença Normalizada (IVDN) que é utilizado tanto para o monitoramento quanto para comparações interanuais de cobertura vegetal (Jensen, 2006), os mapas de expansão urbana da cidade de Campina Grande (Paraíba) disponibilizados pela Secretaria Municipal de Planejamento, Gestão e Transparência (SEPLAN), bem como realizou-se visitas em campo para verificar a correspondência entre os resultados do processamento digital e a área de estudo. Sendo assim, utilizaram-se 60 pontos geográficos de controle obtidos com auxílio do Global Navigation Satellite System, GNSS (Sistema de Navegação Global por Satélite), usando o GPSMAP Garmin 64S. É oportuno ressaltar que as etapas de processamento para gerar o IVDN das imagens capturadas pelo Landsat 5 incluíram calibração radiométrica, reflectância monocromática e IVDN e para a imagem do Landsat 8 compreendeu reflectância do topo da superfície e IVDN, conforme descrito em material suplementar.

O uso e ocupação da terra na área de estudo foi classificada em: corpo hídrico, área construída (exemplo: edificações e pavimentação), solo exposto, gramínea/pastagem, vegetação arbustiva e vegetação arbórea. Avaliou-se a acurácia da classificação semi-supervisionada de uso e ocupação do solo dos mapas temáticos gerados, através de Matriz de Confusão sugerida por Congalton (1991), de maneira que foi verificada a concordância das áreas de treino (áreas atribuídas pelo usuário) com as áreas de validação (dados obtidos em campo). Sendo assim, analisou-se a exatidão global (equação 1) e o Índice Kappa (equação 2).

$$
P_{0}=\frac{\sum_{i=1}^{r} X_{i i}}{N}
$$

Em que: $\mathrm{P}_{0}$ é a exatidão global; $r$ representa o número de linhas da matriz; $\mathrm{X}_{\mathrm{ii}}$ corresponde a pontos corretamente classificados; e $\mathrm{N}$ é o número total de pontos contemplados na matriz.

$$
K=\frac{N \sum_{i=1}^{r} X_{i i}-\sum_{i=1}^{r}\left(X_{i+} * X_{+i}\right)}{N^{2}-\sum_{i=1}^{r}\left(X_{i+*} X_{+i}\right)}
$$

Em que: $\mathrm{K}$ representa o Índice Kappa; e $\mathrm{X}_{\mathrm{i}+}$ e $X_{+i}$ compreendem totais marginais da linha i e coluna i, respectivamente.

Os valores do Índice Kappa variam de zero a um, de modo que resultado próximo a zero significa que a classificação do uso e ocupação da terra foi péssima, ou seja, a classificação realizada não foi melhor que uma classificação obtida através de pixels aleatórios, enquanto que valor igual a um corresponde a excelente classificação (Congalton, 1991; Congalton \& Green, 1999). Utilizou-se os critérios de avaliação proposto por Congalton \& Green (1999) para analisar o grau de concordância da classificação temática, conforme Tabela 2.

TABELA 2 - Critérios utilizados na avaliação do grau de concordância

\begin{tabular}{|c|c|}
\hline Índice Kappa & Concordância \\
\hline $\mathrm{K}<0$ & Péssimo \\
\hline $0,0<\mathrm{K}<0,2$ & Ruim \\
\hline $0,2<\mathrm{K}<0,4$ & Razoável \\
\hline $0,4<\mathrm{K}<0,6$ & Bom \\
\hline $0,6<\mathrm{K}<0,8$ & Muito Bom \\
\hline $0,8<\mathrm{K}<1,0$ & Excelente \\
\hline
\end{tabular}
da classificação temática com base no Índice Kappa (K).

FONTE: Congalton \& Green (1999). 


\subsection{Estimativa de valor de serviços ecossistêmicos}

Os valores de serviços ecossistêmicos (VSE) por categoria de uso e ocupação da terra foram estimados através do método de transferência de benefício. Esse método corresponde à extrapolação ou à transferência de resultados de um ou mais estudos para outra área de contexto similar (Johnston et al., 2015). Nesta pesquisa utilizou-se a média de valor monetário de serviços ecossistêmicos obtidos por de Groot et al. (2012), que estimaram o valor global de serviços ecossistêmicos para 10 biomas e 22 funções ecossistêmicas, utilizando 665 pontos de dados oriundos da triagem de 181 publicações com casos de estudo distribuídos em todo o mundo.

Comparou-se os biomas estudados por de Groot et al. (2012) com os tipos de categoria de uso e ocupação da terra desta pesquisa, sendo estabelecido o bioma que representava melhor cada categoria de uso e ocupação da terra (Tabela 3). As categorias gramínea/pastagem, vegetação arbustiva e arbórea neste estudo corresponde a estratificação vegetal. Considerou-se que na categoria gramínea/ pastagem há predomínio de gramíneas e que a vegetação arbórea oferece mais serviços ecossistêmicos por apresentar estrutura e composição florística mais íntegra que a vegetação arbustiva.
É oportuno ressaltar que foi estabelecido valor monetário de serviço ecossistêmico zero para as categorias solo exposto e área construída, pois para a Microbacia Hidrográfica estudada, foram áreas em que há intenso impacto negativo de atividade humana. As áreas de solo exposto representaram terras sem vegetação ou degradadas e estradas, já as áreas construídas foram caracterizadas pelo predomínio de casas, de prédios e de estradas pavimentadas que tornam esta categoria de uso e de ocupação da terra impermeável.

Os valores médios de serviços ecossistêmicos registrados por de Groot et al. (2012) foram ajustados ao Índice de Preços ao Consumidor (IPC) de novembro de 2017, em dólar (US\$) (Tabela 4), utilizando a calculadora de inflação da US Bureau of Labor Statistics disponível no site https://www. bls.gov/data/inflation_calculator.htm. Dezembro de 2007 foi mês e ano base de entrada do dado.

Embora a aplicação do método de transferência de benefício através de média de valor monetário de serviços ecossistêmicos oriundo de metanálise seja criticado por suas incertezas (Nelson et al., 2009), o mesmo é empregado de forma alternativa para estimar o valor de serviço ecossistêmico, sobretudo em áreas em que há restrições de ordem financeira, de tempo e de disponibilidade de informações para realizar a valoração de serviços a nível

TABELA 3- Equivalência entre biomas estudados por de Groot et al. (2012) e a categoria de uso e ocupação da terra da Microbacia Hidrográfica Riacho das Piabas, Paraíba, Brasil.

\begin{tabular}{lccc}
\hline \multicolumn{1}{c}{ Biomas estudados por de Groot et al. (2012) } & $\begin{array}{c}\text { Número de } \\
\text { pesquisa }\end{array}$ & $\begin{array}{c}\text { Dados de } \\
\text { entrada }\end{array}$ & $\begin{array}{c}\text { Categoria de uso e ocupação da } \\
\text { terra }\end{array}$ \\
\hline $\begin{array}{l}\text { Lagos e rios de água doce } \\
\text { fresh water lakes and rivers) }\end{array}$ & 14 & 15 & Corpo hídrico \\
\hline Pastagem (grasslands) & 16 & 32 & Gramínea/pastagem \\
\hline Bosque (woodlands) & 7 & 21 & Vegetação arbustiva \\
\hline Floresta tropical (tropical forest) & 4 & 96 & Vegetação arbórea \\
\hline
\end{tabular}


TABELA 4- Lista de serviços ecossistêmicos e seus respectivos valor médio de serviço ecossistêmico de acordo com de Groot et al. (2012) por bioma, ajustados ao Índice de Preços ao Consumidor de novembro de 2017 (US\$ por ha-1 $\mathrm{a}^{-1}$ ).

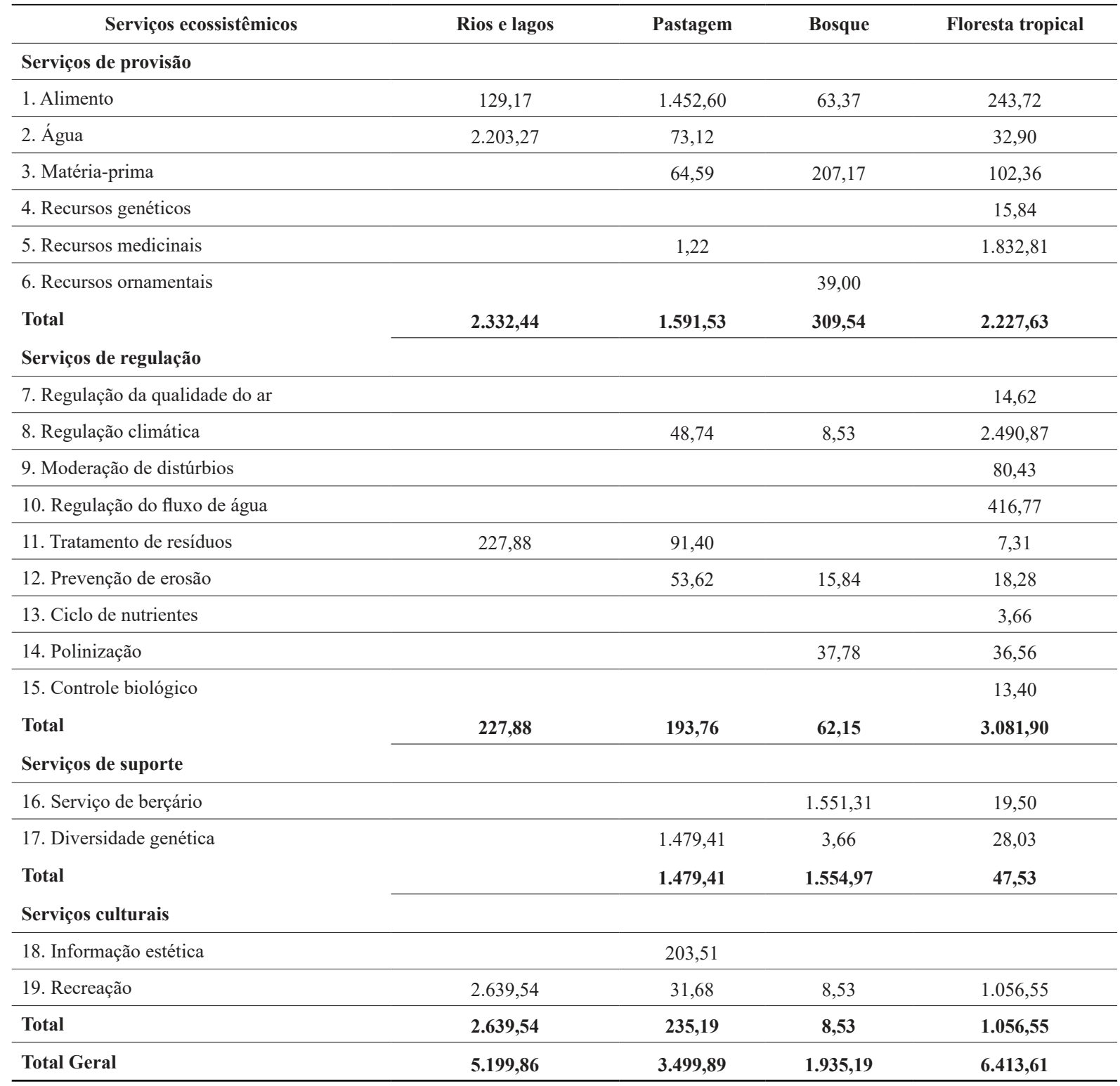


local (Kreuter et al., 2001; Johnston et al., 2015; Kindu et al., 2016; Tolessa et al., 2017; Yi et al., 2017). Diante do exposto, a estimativa do valor total de serviços ecossistêmicos foi obtida a partir da equação 3 utilizada por Hu et al. (2001).

$$
\mathrm{VSE}=\sum \mathrm{A}_{\mathrm{k}} \times \mathrm{CV}_{\mathrm{k}}
$$

Em que: VSE corresponde a estimativa do valor de serviço ecossistêmico; $\mathrm{A}_{\mathrm{k}}$ é a área da categoria $\mathrm{k}$ de uso e ocupação da terra (ha); e $\mathrm{CV}_{\mathrm{k}}$ é o valor médio de serviço ecossistêmico por categoria de uso e ocupação da terra (US\$ ha ${ }^{-1} \mathrm{a}^{-1}$ ) extraído da pesquisa de de Groot et al. (2012), conforme tabela 4.

Adicionalmente, foi estimado o valor de 19 tipos de funções ecossistêmicas (Tabela 4) para a paisagem estudada, sendo empregada a seguinte equação como sugere Hu et al. (2008).

$$
\mathrm{VSE}_{\mathrm{f}}=\sum \mathrm{A}_{\mathrm{k}} \times \mathrm{CV}_{\mathrm{fk}}
$$

Em que: $\mathrm{VSE}_{\mathrm{f}}$ é a estimativa do valor de função de serviço ecossistêmico e $\mathrm{CV}_{\mathrm{fk}}$ corresponde ao valor médio de função de serviço ecossistêmico de dada categoria (US\$ ha ${ }^{-1} \mathrm{a}^{-1}$ ) extraído da pesquisa de de Groot et al. (2012), conforme tabela 4.

A variação percentual ou percentagem relativa (PR) foi calculada para verificar as mudanças de área por categoria de uso e ocupação da terra (ha) e de valor de serviço ecossistêmico entre os anos estudados (US\$). Além disso, aplicou-se a análise de sensibilidade, seguindo o método econômico padrão, conforme literatura especializada (Kreuter et al., 2001; Hu et al., 2008) para minimizar as incertezas dos valores médios de serviços ecossistêmicos propostos por de Groot et al. (2012). A partir desse método foi possível identificar a robustez e razoabilidade do valor de serviço ecossistêmico estimado. Para tanto, foram ajustados $\mathrm{em} \pm 50 \%$ os valores médios extraídos da pesquisa realizada por de Groot et al. (2012) para as seguintes categorias de uso e ocupação da terra: corpo hídrico, gramíneas/ pastagem, vegetação arbustiva e vegetação arbórea. Posteriormente, utilizou-se a equação 5 (Mansfield, 1985) indicada por Kreuter et al. (2001).

$$
\mathrm{CS}=\frac{\left(\mathrm{VSE}_{\mathrm{j}}-\mathrm{VSE}_{\mathrm{i}}\right) / \mathrm{VSE}_{\mathrm{i}}}{\left(\mathrm{CV}_{\mathrm{jk}}-\mathrm{CV}_{\mathrm{ik}}\right) / \mathrm{CV}_{\mathrm{ik}}}
$$

Em que: CS é o coeficiente de sensibilidade; $\mathrm{VSE}_{\mathrm{i}}$ representa o valor inicial de serviço ecossistêmico (US\$ ha $\left.{ }^{-1} \mathrm{a}^{-1}\right) ; V_{\mathrm{VSE}}$ é o valor ajustado de serviço ecossistêmico (US\$ ha ${ }^{-1}$ ano $^{-1}$ ); $\mathrm{CV}_{\mathrm{ik}}$ é o valor médio inicial extraído da pesquisa de de Groot et al. (2012) para categoria $\mathrm{k}$ de uso e ocupação da terra (US\$ ha ${ }^{-1}$ $\left.\mathrm{a}^{-1}\right) ; \mathrm{eCV}_{\mathrm{jk}}$ representa o valor médio ajustado extraído da pesquisa de de Groot et al. (2012) para categoria $\mathrm{k}$ de uso e ocupação da terra (US\$ ha $\mathrm{a}^{-1} \mathrm{a}^{-1}$ ).

$\mathrm{Se} \mathrm{CS}$ for $<1$, o valor estimado de serviço ecossistêmicos é inelástico, representando que tais valores são aceitáveis e a análise é robusta. Se CS for $>1$, então o valor estimado de serviços ecossistêmicos é elástico.

\section{Resultados}

\subsection{Mudança do uso e ocupação da terra}

A distribuição espacial e temporal do uso e ocupação da terra na MBHRP entre anos de 1989 e 
2014 apresentaram diferenças marcantes (Figura 2). atingindo 115\% (Tabela 5). A área construída foi a Neste período, em termos de porcentagem relativa, categoria dominante, em todos os anos estudados, as categorias de vegetação arbustiva e arbórea so- seguida da categoria de gramínea/pastagem (Tabela freram a maior diminuição, com perda estimada de 5). No entanto, a cobertura de gramínea/pastagem $76 \%$ cada uma e a área construída o maior aumento,
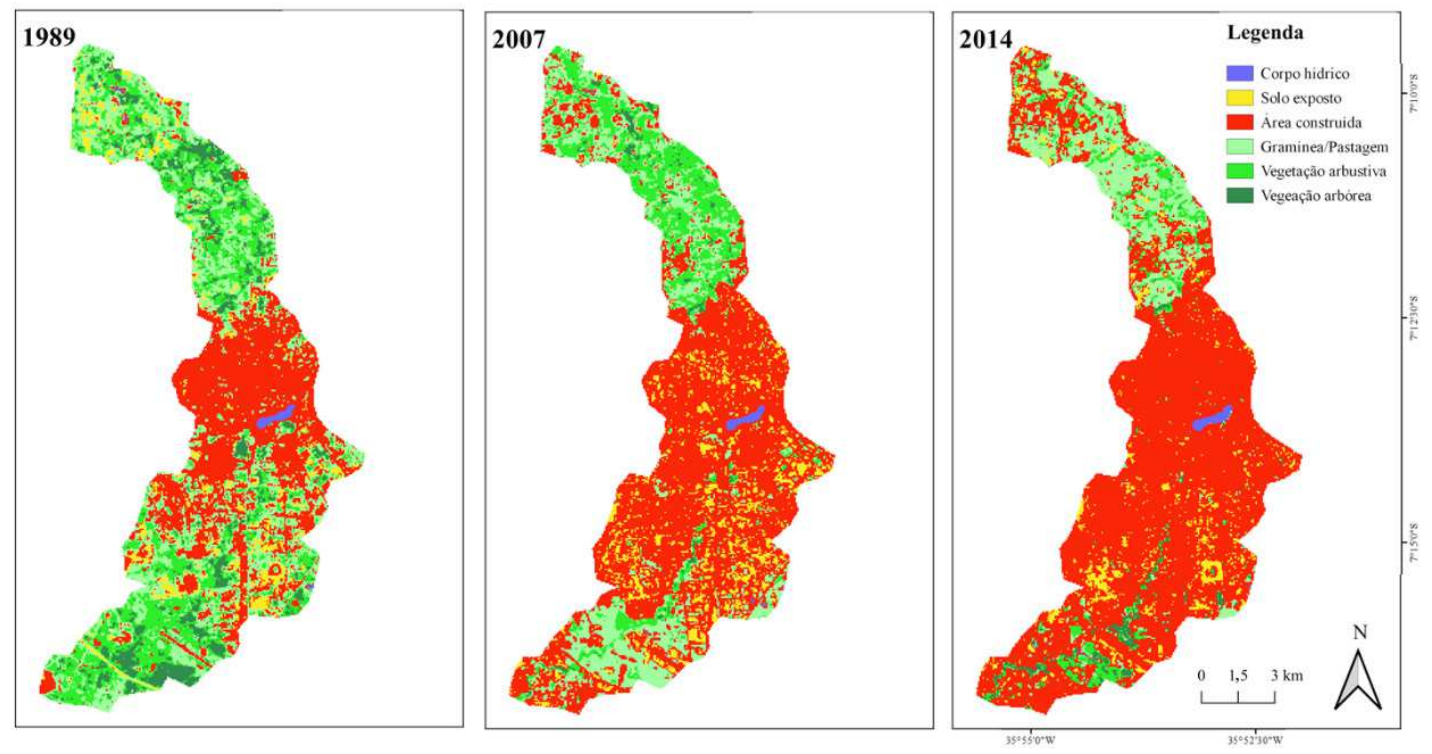

FIGURA 2 - Uso e ocupação da terra em 1989, 2007 e 2014 na Microbacia Hidrográfica Riacho das Piabas, Campina Grande, PB, Brasil.

TABELA 5- Mudança no uso e ocupação da terra, período 1989-2014, na Microbacia Hidrográfica Riacho das Piabas, região metropolitana de Campina Grande, PB, Brasil.

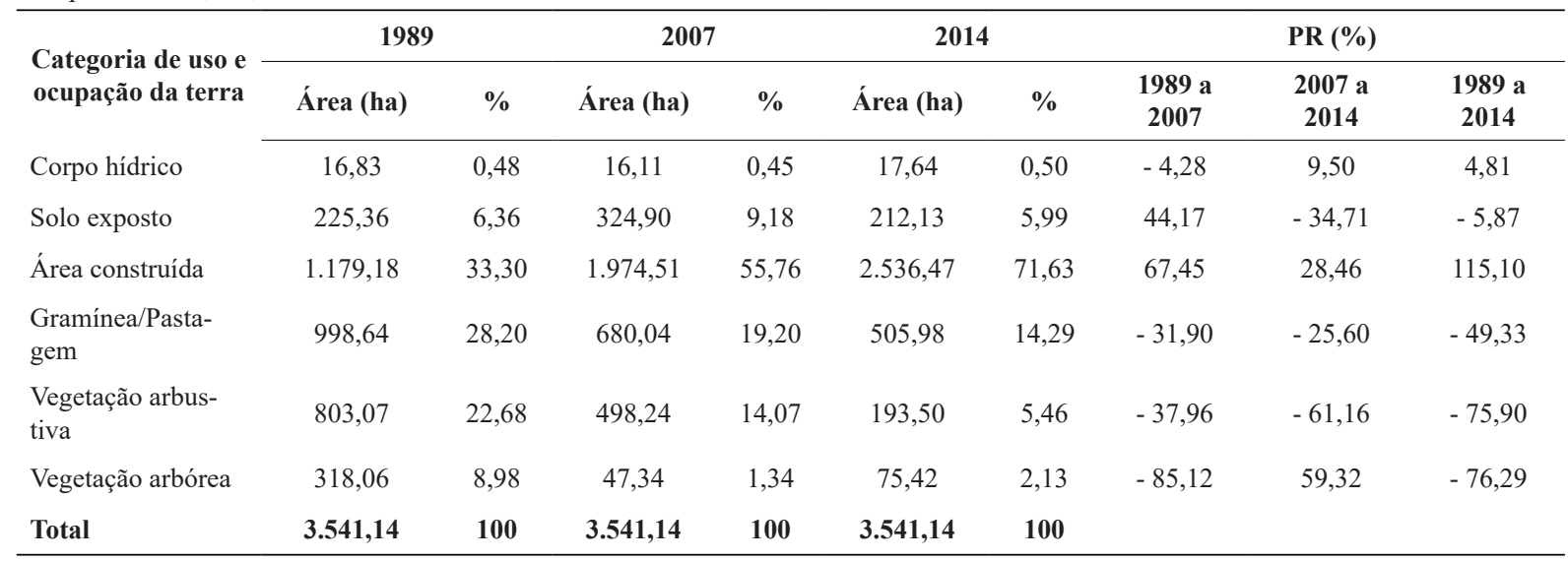


diminuiu durante os anos, alcançando perda de $49 \%$ entre o período de 1989 e 2014.

A vegetação arbustiva cobria $23 \%$ da área de estudo em 1989, sobressaindo nos setores mais ao Norte e mais ao Sul (Figura 2). Já em 2014 esta categoria foi substituída em taxa média de 24 ha $\mathrm{a}^{-1}$ por gramínea/pastagem no setor Norte e por ocupação urbana nas outras áreas (Figura 2). A área construída aumentou rapidamente (67\%) entre 1989 e 2007 (média de 44 ha a $^{-1}$ ) passando de 33,30\% para $55,76 \%$ da área de estudo no período analisado, refletindo o rápido crescimento urbano de Campina Grande no setor central da MBHRP (Figura 2). A área construída aumentou 28,46\% entre 2007 e 2014 (Tabela 5), expandindo principalmente no setor Sul (Figura 2), em média 80 ha a $^{-1}$.

As categorias de corpo hídrico e de vegetação arbórea apresentaram diminuição de área entre 1989 e 2007 e aumento entre 2007 e 2014 (Tabela 5). Todavia, no período de 1989 a 2014, a área ocupada por corpo hídrico aumentou $4,81 \%$, enquanto que a extensão territorial de vegetação arbórea diminuiu $76 \%$. Em contraste, a categoria de solo exposto apresentou aumento de $44,17 \%$ no período de 1989 e 2007 e subsequente perda de $34,71 \%$ entre 2007 e 2014 (Tabela 5), sendo substituída por área construída.

\subsection{Análise de acurácia}

A precisão dos mapas temáticos de uso e ocupação da terra da MBHRP, produzidos a partir da classificação semi-supervisionada, possuíram muito boa concordância entre a verdade terrestre e o mapa temático de 1989, apresentando exatidão geral de $82,33 \%$ e valor de índice Kappa igual a 0,77 ; e excelente concordância para os mapas temáticos de $2007\left(\mathrm{P}_{0}=95,20 \%\right.$ e $\left.\mathrm{K}=0,93\right)$ e de $2014\left(\mathrm{P}_{0}=96,72 \%\right.$ e $\left.\mathrm{K}=0,96\right)$, conforme tabela 6. Registrou-se divergências ocorridas entre as categorias temáticas, ao analisar a matriz de erros, sobretudo para o mapa temático referente ao ano de 1989. Como exemplo, a categoria de corpo hídrico apresentou baixa uniformidade, de modo que pixels enquadrados em gramínea/pastagem e vegetação arbustiva foram classificados como corpo hídrico (Tabela 6). É oportuno ressaltar que o aumento do número de áreas de treino para o ano de 1989 resultou em aumento de confusão na classificação da imagem e mesmo diante de tal divergência os mapas temáticos de uso e ocupação da terra gerados para analisar os serviços ecossistêmicos na MBHRP foram satisfatórios, o que assegura a confiabilidade do presente estudo.

\subsection{Mudanças na oferta e nos valores totais de serviços ecossistêmicos}

A disponibilidade de serviços ecossistêmicos prestados pela MBHRP diminuiu quando foi considerado as mudanças nos valores totais estimados de serviços ecossistêmicos para o período estudado (Tabela 7). O valor total estimado de serviço ecossistêmico por hectare para o ano de 1989 foi igual a US\$ 7,18 milhões, para o ano de 2007 foi de US\$ 3,73 milhões e para o ano de 2014 foi igual a US\$ 2,72 milhões, apresentando redução de $62,09 \%$ entre os anos de 1989 e 2014, equivalendo a perda líquida de US\$ 4,5 milhões ou US\$ 178 mil ao ano (Tabela 7). A taxa de perda de valor estimado de serviços ecossistêmicos foi US\$ 191,39 mil por ano entre 1989 e 2007 e US\$ 144,41 mil ao ano no período de 2007 a 2014. 
Tabela 6 - Distribuição de valor de acurácia e do Índice de Kappa por categoria de uso e ocupação da terra para os anos de 1989,2007 e 2014 da Microbacia Hidrográfica Riacho das Piabas, Paraíba, Brasil.

\begin{tabular}{|c|c|c|c|c|c|c|c|c|c|}
\hline $\begin{array}{c}\text { Categoria de uso } \\
\text { e ocupação da } \\
\text { terra }\end{array}$ & \multicolumn{3}{|c|}{1989} & \multicolumn{3}{|c|}{2007} & \multicolumn{3}{|c|}{2014} \\
\hline Corpo hídrico & 21,46 & 100,00 & 1,00 & 98,02 & 100,00 & 1,00 & 99,49 & 100,00 & 1,00 \\
\hline Solo exposto & 100,00 & 100,00 & 1,00 & 99,25 & 86,60 & 0,85 & 92,47 & 100,00 & 1,00 \\
\hline $\begin{array}{l}\text { Gramínea/Pas- } \\
\text { tagem }\end{array}$ & 91,78 & 41,79 & 0,38 & 98,03 & 96,06 & 0,93 & 99,66 & 94,64 & 0,92 \\
\hline $\begin{array}{l}\text { Vegetação arbus- } \\
\text { tiva }\end{array}$ & 94,94 & 75,19 & 0,68 & 92,46 & 98,14 & 0,98 & 78,14 & 91,70 & 0,91 \\
\hline Vegetação arbórea & 97,19 & 92,59 & 0,89 & 94,74 & 100,00 & 1,00 & 94,38 & 98,76 & 0,99 \\
\hline
\end{tabular}

TABELA 7 - Valor total estimado de serviço ecossistêmico (US\$) por categoria de uso e ocupação da terra na Microbacia Hidrográfica Riacho das Piabas, Paraíba, Brasil, usando a base de dados elaborada por de Groot et al. (2012) ajustado para novembro de 2017 e porcentagem relativa (PR) entre o período de estudo (1989 a 2014).

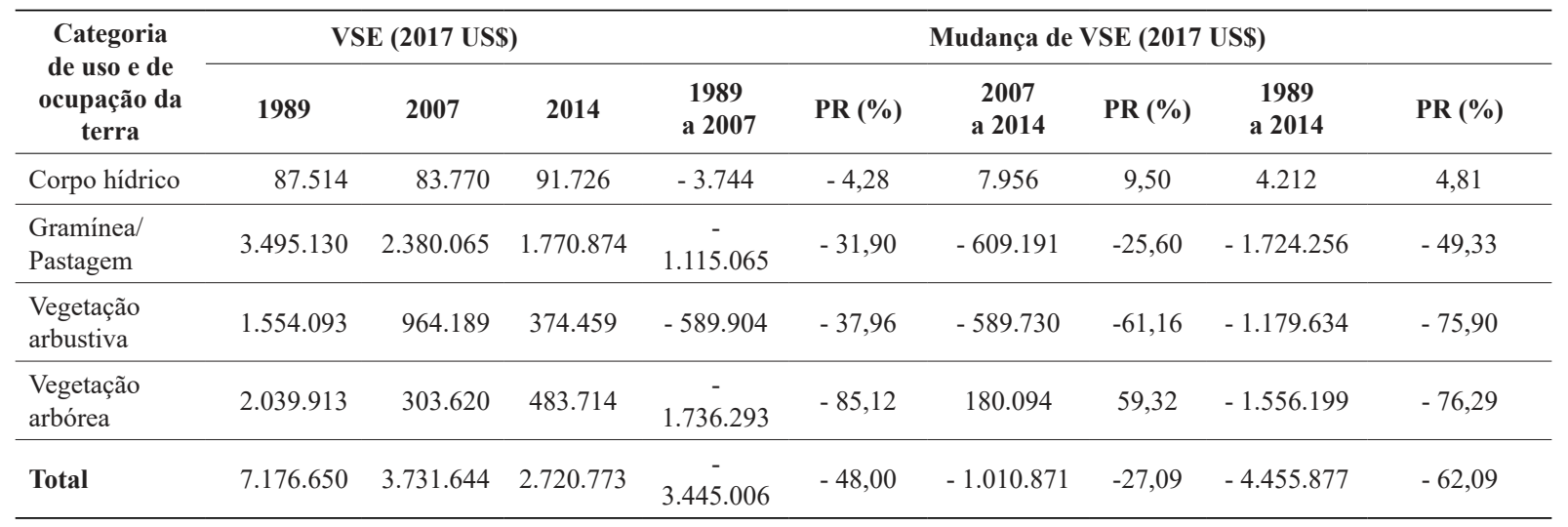


A redução da disponibilidade de serviços ecossistêmicos ao longo dos anos decorreu do aumento de área construída e diminuição de áreas verdes (vegetação arbustiva e arbórea), sobretudo da categoria vegetação arbórea (Tabela 7), que teve o valor monetário estimado de serviços ecossistêmicos reduzido a uma taxa anual de US\$62,25 mil, correspondendo a perda de $34,92 \%$ da disponibilidade de serviços ecossistêmicos na área de estudo entre os anos 1989 e 2014, bem como da redução da categoria gramínea/pastagem (Tabela 7). Em contrapartida, a categoria corpo hídrico apresentou discreto aumento na disponibilidade de serviços ecossistêmicos, entre 1989 e 2014 (Tabela 7).

Com o decréscimo das áreas arbustivas e arbóreas, a importância da contribuição relativa das categorias corpo hídrico e gramíneas/pastagem no ESV total foi elevada ao longo dos anos, de modo que a categoria de corpo hídrico aumentou sua contribuição no VSE total de 1,22\% (1989) para 3,37\% (2014), as áreas de gramíneas/pastagem apresentaram elevação de sua contribuição de 48,70\% em 1989 para 65,09\% em 2014 (Tabela 7). Já a contribuição no VSE total da categoria de vegetação arbustiva e vegetação arbórea juntas era 50,08\% em 1989 e em 2014 31,54\%, apresentando redução de 37,02\% em relação a contribuição inicial (1989) (Tabela 7). Todos os valores estimados de funções de serviços ecossistêmicos diminuíram no período de 1989 a 2014. Porém, os serviços ecossistêmicos recursos genéticos, recursos medicinais, regulação da qualidade do ar, regulação climática, moderação de distúrbios, regulação do fluxo de água, ciclo de nutrientes, controle biológico e recreação apresentaram aumento entre o período de 2007 e 2014 (Tabela 8).

A ordem dos três tipos de funções ecossistêmicas (alimento, diversidade genética e serviço de berçário) que mais contribuíram no VSE total não variou entre os anos estudados, apenas a sua percentagem de contribuição por ano foi alterada. Nesse contexto, em 1989, 60\% do VSE total foi resultante da disponibilidade dessas três funções ecossistêmicas, que em 2007 equivaleu a $75 \%$ e em 2014 correspondeu a $67 \%$ do VSE total (Tabela 8). Entre os anos de 1989 e 2014, 10 funções ecossistêmicas (controle biológico, ciclo de nutriente, regulação do fluxo de água, moderação de distúrbio, regulação da qualidade de ar, recursos genéticos, recursos medicinais, polinização, serviço de berçário e recursos ornamentais) apresentaram variação relativa negativa, ocorrendo redução na disponibilidade desses serviços ecossistêmicos maior que $75 \%$ (Tabela 8 ).

\subsection{Análise de sensibilidade de serviço ecossistêmico}

O coeficiente de sensibilidade apresentou variação mínima de $\pm 0,012 \mathrm{a} \pm 0,183$ para a categoria corpo hídrico e máxima de $\pm 0,217 \mathrm{a} \pm 0,65$ para a categoria gramínea/pastagem, quando os valores de serviços ecossistêmicos foram ajustados em $\pm 50 \%$ (Tabela 9). Os valores registrados para os CS foram menores que um para todas as categorias de uso e ocupação da terra analisadas por ano (Tabela 9). Sendo assim, os valores estimados para bens e serviços ecossistêmicos prestados pela MBHRP são relativamente inelásticos (baixa sensibilidade) em relação aos valores médios de serviços ecossistêmicos estimados por de Groot et al. (2012). Portanto, os valores estimados de serviços do ecossistema para a área de estudo são robustos e razoavelmente aceitáveis. A mudança da disponibilidade de serviços ecossistêmicos entre o período estudado não apresentou diferenças substanciais com o ajuste $\pm 50 \%$ dos VSEs para as categorias recursos hídricos, 
vegetação arbustiva e vegetação arbórea (Tabela 9). 1989 e 2014 foi igual a -61,68\% (US\$ -4,45milhões, Por exemplo, quando apenas o VSE da categoria corpo Tabela 9), próximo ao VSE total registrado quando o hídrico foi aumentado em 50\% a mudança na disponi- VSE não foi ajustado (-62,09\% e US\$ -4,46 milhões, bilidade de serviços ecossistêmicos entre o período de Tabela 7).

TABELA 8 - Valor total estimado de serviço ecossistêmico (US\$ ajustado para IPC de novembro de 2017) por função ecossistêmica da Microbacia Hidrográfica Riacho das Piabas, Paraíba, Brasil e suas respectivas porcentagens relativas entre o período de estudo (1989 a 2014 ).

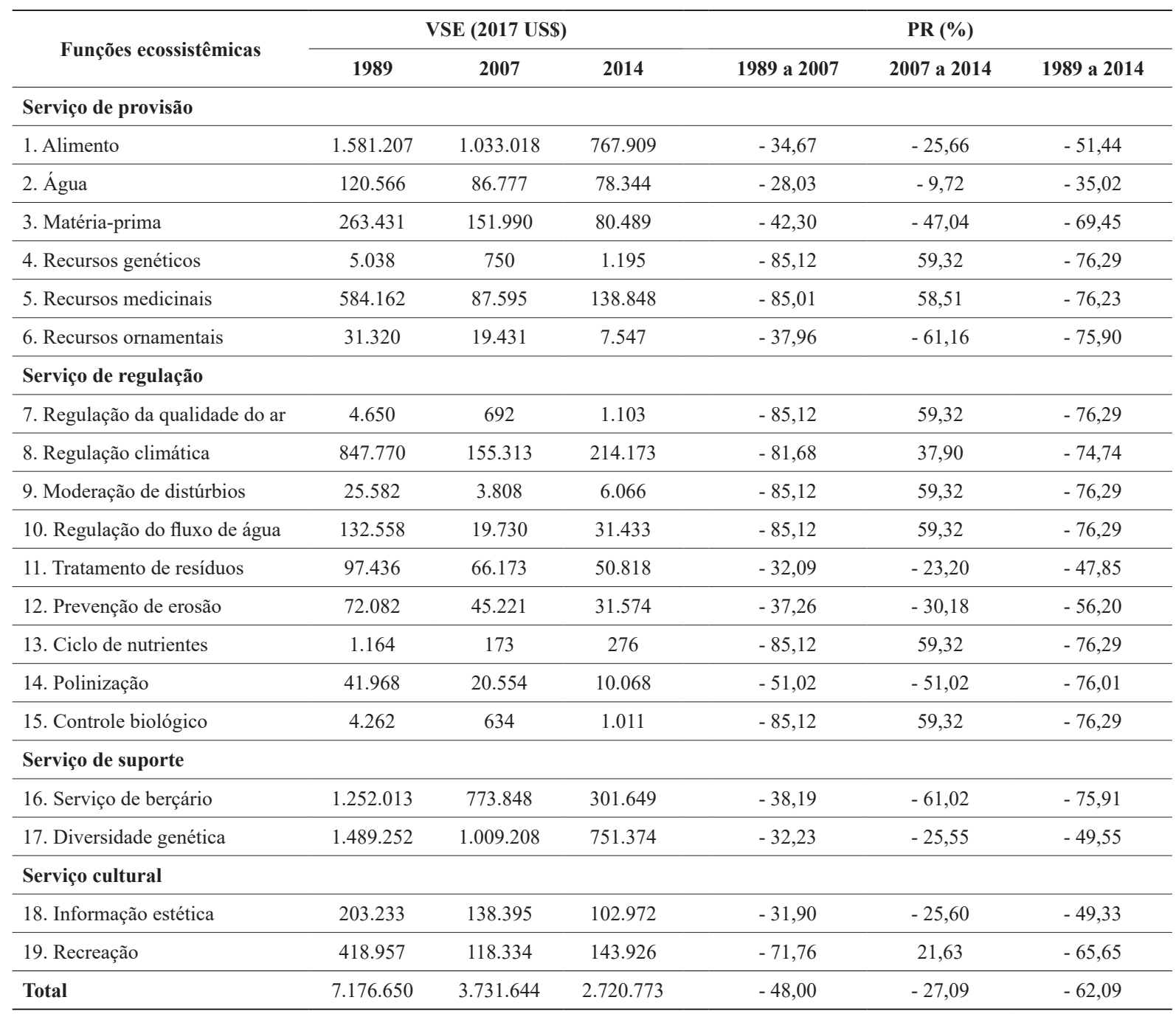


TABELA 9- Valores estimados do serviço do ecossistema total ajustados para $\pm 50 \%$ (VSEa), variação relativa de VSEa ao longo do tempo (\%) e o coeficiente de sensibilidade (CS).

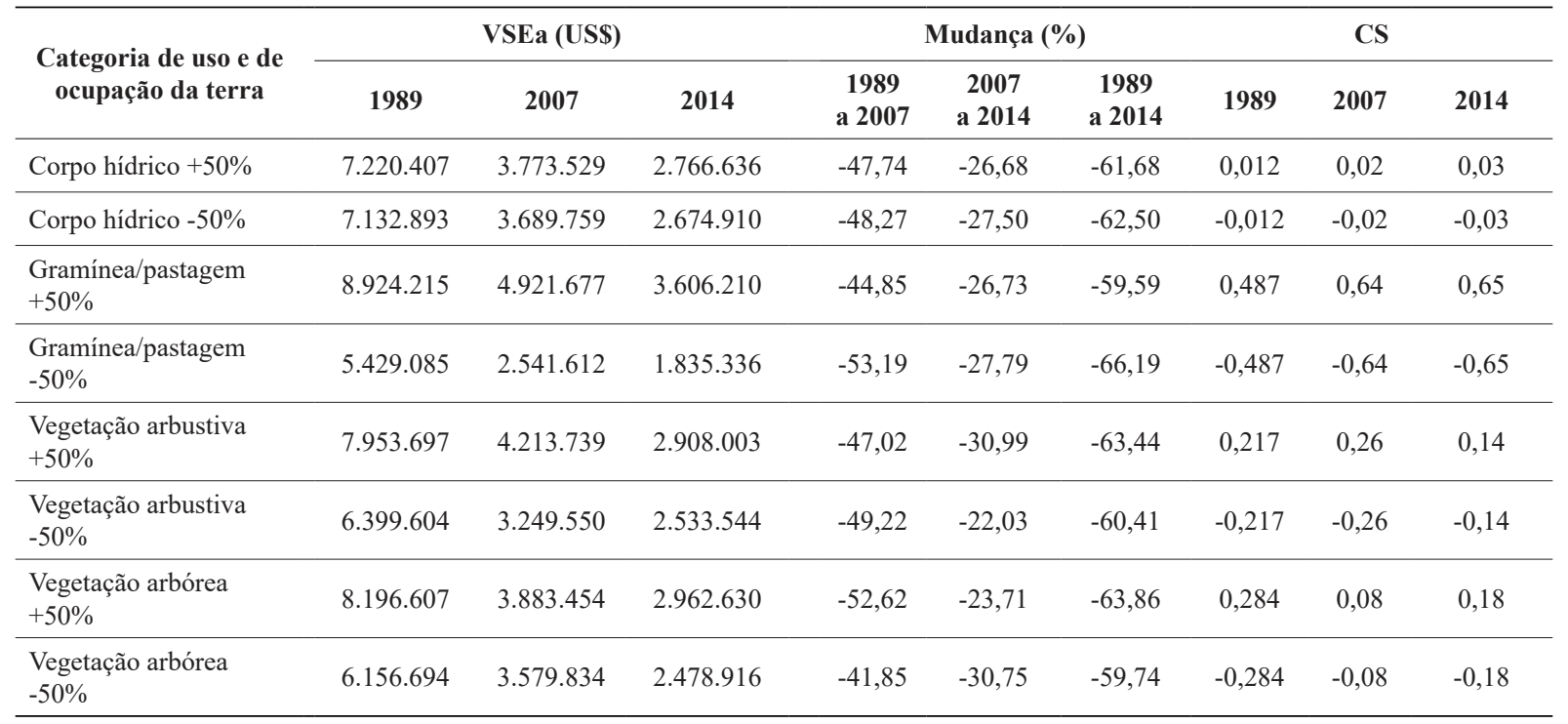

Em contraste, o acréscimo de 50\% do VSE da categoria de gramínea/pastagem, entre 1989 e 2014, resultou em diminuição de oferta de serviços ecossistêmicos em $59,29 \%$, correspondendo a perda anual de US\$212,72 mil, enquanto que a redução do VSE em 50\% causou decréscimo de $66,19 \%$, resultando em diminuição anual de US\$ 143,75 mil (Tabela 9).

\section{Discussão}

A expansão urbana na MBHRP ao longo dos anos estudados interferiu negativamente no valor total estimado e na disponibilização de serviço ecossistêmico relevantes para a manutenção da vida e de atividades socioeconômicas das atuais e das futuras gerações, sobretudo dos serviços fornecidos pelas áreas de vegetação arbustiva e ar- bórea, corroborando os trabalhos desenvolvidos por Mendoza-González et al. (2012), Schneider et al. (2012) e Yi et al. (2017). Nesse estudo, a vegetação arbórea foi a categoria que ofereceu mais funções ecossistêmicas, sendo a categoria mais valiosa, de maneira que mesmo ocupando área três vezes menor que a categoria gramínea/pastagem, em 1989, as áreas cobertas por vegetação arbórea detiveram mais da metade do valor monetário estimado para a categoria gramínea/pastagem (Tabela 7).

As funções ecossistêmicas criticamente afetadas pela mudança no uso e ocupação da terra foram: controle biológico, ciclo de nutriente, regulação do fluxo de água, moderação de distúrbio, regulação da qualidade de ar, recursos genéticos, recursos medicinais, polinização, serviço de berçário e recursos ornamentais. Dessas, 6 funções ecossistêmicas foram registradas apenas para a categoria 
vegetação arbórea. Ademais, a função ecossistêmica de recursos medicinais oferecida pela vegetação arbórea deteve o maior valor médio monetário da base de dados elaborada por de Groot et al. (2012) quando comparado com as demais categorias de uso e ocupação da terra.

O declínio de áreas verdes tende a gerar impactos negativos, por exemplo: nos recursos hídricos (Hümann et al., 2011), na regulação do microclimática (Schneider et al., 2012) e no estoque de carbono (Islam et al., 2017), bem como na infiltração de água no solo, elevando o escoamento superficial que potencializa o deslocamento de partículas da camada superior do solo (erosão) (Hümann et al., 2011; Chen et al., 2017) e inundações (Schneider et al., 2012). Adicionalmente, a impermeabilização do solo (pavimentação), o uso de concreto e o tamanho das edificações em áreas urbanas pode promover maior retenção de calor, e consequentemente desconforto térmico e problemas de saúde (Schneider et al., 2012; Qaid et al., 2016). Nessa perspectiva, a concentração populacional e a ocupação humana desordenada, comum em países em desenvolvimento, associada a perda de habitat e fragmentação florestal, pode ter causado impactos duradouros ou irreversíveis ao meio ambiente e, consequentemente, à qualidade de vida da sociedade da MBHRP.

Os serviços culturais com função de inspiração, experiência espiritual e desenvolvimento cognitivo não apresentaram representação nos tipos de categorias estudadas na área de estudo. No entanto, não significa que essas funções ecossistêmicas inexistem no local, mas sim que não houve valores na base de dados elaborada por de Groot et al. (2012) para aplicar o método de transferência de benefício, o que demostra uma limitação no método (Johns- ton et al., 2015). O curso principal da Microbacia Hidrográfica Riacho das Piabas, especialmente sua porção em que se localiza o Açude Velho é fonte de inspiração para artista, sobretudo poetas. Ademais, localiza-se o Museu de Arte Popular da Paraíba e mais quatro monumentos abordando a luta e conquista da região pelos pioneiros da Borborema e homenageando grandes nomes da cultura nordestina. Além disso, a MBHRP é objeto de estudo de trabalhos científicos e possui relevância histórica para os moradores da cidade de Campina Grande por ter sido em suas margens que a cidade iniciou o seu desenvolvimento.

É oportuno ressaltar que, nesse estudo, a valoração de serviços ecossistêmicos foi realizada com a finalidade de analisar a influência das mudanças espaciais e temporais do uso e ocupação da terra na disponibilidade de serviços ecossistêmicos, uma aplicação comumente aceita (Kreuter et al., 2001; Mendoza-González et al., 2012; Tolessa et al., 2017; Yi et al., 2017). Embora os valores totais estimados de serviços ecossistêmicos para a área de estudo sejam confiáveis, conforme a análise de robustez do coeficiente de sensibilidade, esses são estimativas mínimas para a área de estudo, não sendo incentivado o uso de coeficientes de valor para estabelecer preços unitários (mercantil), visto que a maior parte de bens e serviços ecossistêmicos são públicos, de uso comum e não podem ser privatizados ou tratados como mercadorias (de Groot et al., 2012). Dessa forma, a tomada de decisão deve ser baseada em dados validados para as condições locais. Para tanto, é necessário estudo que abarque as especificidades bióticas e abióticas de modo que possam ser traduzidos em bens e serviços ecossistêmicos da localidade. 
O desenvolvimento da MBHRP, a partir da análise de mudança do uso e ocupação da terra, priorizou os potenciais benefícios socioeconômicos do ambiente construído (centros industriais, comerciais, tecnológicos e universitários para a população local), sem mensurar as consequências da degradação ambiental. As categorias de corpo hídrico, gramínea/pastagens e vegetação arbustiva mantiveram o nível de preferência, evidenciado por pequenas alterações no tamanho da área e no valor total estimado do serviço do ecossistema entre o período analisado. Tal fato ocorre porque a população da MBHRP é majoritariamente abastecida por reservatório de água localizado em um município vizinho e uma grande diversidade de matérias-primas e alimentos são importados de outras localidades. Em vista do exposto, a presente pesquisa corrobora as assertivas de que a mudança no uso e ocupação da terra, ao longo do tempo, é um processo complexo caracterizado pela não-linearidade e dinâmica envolvendo fatores humanos e naturais (Meshesha et al., 2014; Groffman et al., 2017) e que as áreas urbanas dependem da exportação de bens e serviços de ecossistemas de outras regiões (Hails \& Ormerod, 2013).

A criação e a manutenção de infraestrutura verde na zona urbana e periurbana da MBHRP pode melhorar a capacidade do sistema de se adaptar aos efeitos das mudanças climáticas e outras perturbações ambientais (Green et al., 2016), tendo em vista que a área de estudo é vulnerável às mudanças climáticas e susceptível ao processo de desertificação (Vieira et al., 2015; Marengo et al., 2017). A gestão que deseja mitigar o impacto do processo de urbanização na prestação de serviços ecossistêmicos pode considerar a aplicação de gestão baseada em ecossistema, que visa restaurar e conservar os recursos naturais essenciais para a manutenção da vida e do bem-estar humano, além do uso sustentável dos recursos naturais, garantindo os elementos essenciais para a economia e as necessidades das gerações atuais e futuras (Brussard et al., 1998; Munang et al., 2011).

Dessa forma, para aumentar a oferta de serviços ecossistêmicos e reduzir os custos associados à degradação ambiental deve-se considerar ações que: (1) estimulem a conservação da natureza onde há ambiente natural ou pouco alterado; (2) promovam a criação de habitats ou restauração ambiental; (3) regulem ou controlem os tipos e a taxa de uso e ocupação da terra; (4) estabeleçam o pagamento por serviços ecossistêmicos em ambientes estratégicos. Particularmente, no estado Paraíba, a Lei n ${ }^{\circ} 10.165$, de 25 de novembro de 2013, que institui a Política Estadual de Pagamento por Serviços Ambientais (PEPSA) poderia ser aplicada na MBHRP, de modo que os serviços ecossistêmicos de áreas relevantes seriam mantidos através de incentivos financeiros para os proprietários das terras.

\section{Conclusão}

O processo de urbanização ao longo de 25 anos alterou substancialmente a configuração da paisagem da MBHRP, influenciando negativamente o ESV total, de maneira que todas as funções de serviços ecossistêmicos analisadas apresentaram valor monetário estimado reduzido, no período de 1989 a 2014. Os fatores chaves de declínio de ESV total e, consequentemente, da disponibilidade de serviços ecossistêmicos relevantes para o bem-estar humano na MBHRP foram a redução de áreas 
verdes, principalmente da vegetação arbórea e a expansão urbana desordenada.

Foi notório que a variação estimada do valor total de serviços do ecossistema foi sensível ao número de categorias de uso e ocupação da terra que uma determinada função do ecossistema foi enquadrada, ao aumento ou à perda de área e ao valor monetário médio considerado para cada função ecossistêmica na etapa de transferência de benefício. Desta forma, as áreas arborizadas foi a categoria com maior influencia no VSE total de cada ano, pois deteve maior quantidade de funções ecossistêmicas com elevado VSE, sendo a categoria mais valiosa neste estudo.

A diversificação de ambientes naturais que disponibilize funções ecossistêmicas desejáveis pode minorar os efeitos negativos do processo de urbanização. Espaços verdes com maior conectividade e distribuídos na área urbana e periurbana devem ser considerados em ações que priorize elevar a quantidade e melhorar a qualidade de bens e serviços ecossistêmicos.

\section{Agradecimentos}

Os autores Ferreira, L.M.R. e Souza, E.P. agradecem ao Conselho Nacional de Desenvolvimento Científico e Tecnológico (CNPq) pela concessão de bolsa de Estudo e Produtividade em Pesquisa, respectivamente. Esteves, L.S. agradece à Coordenação de Aperfeiçoamento de Pessoal de Nível Superior (CAPES/PVE 88881.068064/2014-01) pelo financiamento do projeto Valoração de Serviços Ambientais Aplicados a Vulnerabilidade Costeira (VALSA) em que é professora visitante especial.

\section{Referências}

AESA - Agência Executiva de Gestão das Águas do Estado da Paraíba. Geoportal, 2010. Disponível em: <http:// geoserver.aesa.pb.gov.br/geoprocessamento/geoportal/ sigaesaweb.html >. Acesso em: out. 2016.

Baker, J.; Sheate, W. R.; Phillips, P.; Eales, R. Ecosystem services in environmental assessment - Help or hindrance? Environmental Impact Assessment Review, 40, 3-13, 2013. doi: 10.1016/j.eiar.2012.11.004

Brasil. Lei $n . .^{\circ}$ 9.433, de 8 de janeiro de 1997. Institui a Política Nacional de Recursos Hídricos. Brasília: DOU de 09/1/1997.

Brasil. Lei n..$^{\circ}$ 12.651, de 25 de maio de 2012. Dispõe sobre a proteção da vegetação nativa. Brasília: DOU de 28/5/ 2012.

Brussard, P. F.; Reed, J. M.; Tracy, C. R. Ecosystem management: what is it really? Landscape and Urban Planning, 40, 9-20, 1998. doi: 10.1016/S0169-2046(97)00094-7

Câmara, E. Os alicerces de Campina Grande: esboço histórico-social do povoado e da vila (1697-1864). Campina Grande: Editora Caravela, 3. ed., 2006.

Chen, J.; Theller, L.; Gitau, M. W.; Engel, B. A.; Harbor, J. M. Urbanization impacts on surface runoff of the contiguous United States. Journal of Environmental Economics and Management, 187, 470-481, 2017. doi: 10.1016/j. jenvman.2016.11.017

Congalton, R. G. A review of assessing the accuracy of classifications of remotely sensed data. Remote Sensing of Environment, 37, 35-46, 1991. doi: 10.1016/00344257(91)90048-B

Congalton, R.G.; Green, K. Assessing the Accuracy of Remotely Sensed Data: Principles and Practices. Nova York: Lewis Publishers, 1999.

Costanza, R.; de Groot, R.; Sutton, P.; Van der Ploeg, S.; Anderson, S. J.; Kubiszewski, J.; Farber, S.; Turner, R. K. Changes in the global value of ecosystem services. Global Environmental Change, 26, 152-158, 2014. doi: 10.1016/j. gloenvcha.2014.04.002

de Groot, R. S.; Brander, L.; Van der Ploeg, S.; Costanza, 
R.; Bernard, F.; Braat, L.; Christie, M.; Crossman, N.; Ghermandi, A.; Hein, L.; Hussain, S.; Kumar, P.; McVittie, L.; Portela, R.; Rodriguez, L. C.; Brinkm, P.; Van Beukering, P. Global estimates of the value of ecosystems and their services in monetary units. Ecosystem Services, 1, 50-61, 2012. doi: 10.1016/j.ecoser.2012.07.005.

Elmqvist, T.; Fragkias, M.; Goodness, J.; Güneralp, B.; Marcotullio, P. J.; McDonald, R. I.; Parnell, S.; Schewenius, M.; Sendstad, M.; Seto, K. C.; Wilkinson, C. Urbanisation, biodiversity and ecosystem services: challenges and opportunities. Dordrecht: Springer, 2013.

Evangelista, A. R. S. O processo de ocupação do bioma caatinga e suas repercussões socioambientais na Sisalândia, Bahia. Salvador, Dissertação (Mestrado em Geografia) - UFBA, 2010.

Fragkias, M.; Güneralp, B.; Seto, K. C.; Goodness, J. A synthesis of global urbanisation projections. In: Elmqvist, T.; Fragkias, M.; Goodness, J.; Güneralp, B.; Marcotullio, P. J.; McDonald, R. I.; Parnell, S.; Schewenius, M.; Sendstad, M.; Seto, K. C.; Wilkinson, C. (Eds.) Urbanisation, biodiversity and ecosystem services: challenges and opportunities. Dordrecht: Springer, p. 409-435, 2013.

Green, T. L.; Kronenberg, J.; Andersson, E.; Elmqvist, T.; Gómez-Baggethun, E. Insurance value of green infrastructure in and around cities. Ecosystems, 19, 1051-1063, 2016. doi: 10.1007/s10021-016-9986-x

Groffman, P. M.; Cadenasso, M. L.; Cavender-Bares, J.; Childers, D. L.; Grimm, N. B.; Grove, J. M.; Hobbie, S. E.; Hutyra, L. R.; Jenerette, G. D.; McPhearson, T.; Pataki, D. E.; Pickett, S. T. A.; Pouyat, R. V.; Rosi-Marshall, E.; Ruddell, B. L. Moving towards a new urban systems science. Ecosystems, 20, 38-43, 2017. doi:10.1007/s10021016-0053-4

Hails, R. S.; Ormerod, S. J. Ecological science for ecosystem services and the stewardship of natural capital. Journal of Applied Ecology, 50, 807-811, 2013. doi: 10.1111/13652664.12127

Hu, H.; Liu, W.; Cao, M. Impact of land use and land cover changes on ecosystem services in Menglun, Xishuangbanna, Southwest China. Environmental Monitoring and Assessment, 146, 146-156, 2008. doi: 10.1007\%2Fs10661-007-
0067-7

Hümann, M.; Schüler, G.; Müller, C.; Schneider, R.; Johst, M.; Caspari, T. Identification of runoff processes - The impact of different forest types and soil properties on runoff formation and floods. Journal of Hydrology, 409, 637-649, 2011. doi: 10.1016/j.jhydrol.2011.08.067

IBGE - Instituto Brasileiro de Geografia e Estatística. Mapa de biomas e de vegetação, 2004. Disponível em: <http:// www.ibge.gov.br/home/presidencia/noticias/2105 2004biomas.shtm>. Acesso em: jul. 2015.

INMET - Instituto Nacional de Meteorologia. Banco de Dados Meteorológicos para Ensino e Pesquisa, 2015. Disponível em: <http://www.inmet.gov.br/portal/index. php?r=bdmep/bdmep $>$. Acesso em: out. 2016.

Islam, M.; Deb, G. P.; Rahman, M. Forest fragmentation reduced carbon storage in a moist tropical forest in Bangladesh: Implications for policy development. Land Use Policy, 65, 15-25, 2017. doi: 10.1016/j.landusepol.2017.03.025

Jensen, J. R. Remote sensing of the environment: an earth resource perspective. Nova Jersey: Pearson Prentice-Hall. 2. ed., 2006.

Johnston, R. J.; Rolfe, J.; Rosenberger, R. S.; Brouwer, R. Benefit transfer of environmental and resource values: a guide for researchs and practitioners. Berlim: Springer, 2015.

Kindu, M.; Schneider, T.; Teketay, D.; Knoke, T. Changes of ecosystem service values in response to land use/land cover dynamics in Munessa-Shashemene landscape of the Ethiopian highlands. Science of the Total Environment, 547, 137-147, 2016. doi:10.1016/j.scitotenv.2015.12.127

Kottek, M.; Grieser, J.; Beck, C.; Rudolf, B.; Rubel, F. World Map of the Köppen-Geiger climate classification updated. Meteorologische Zeitschrift, 15, 259-263, 2006. doi: 10.1127/0941-2948/2006/0130.

Kreuter, U. P.; Harris, H. G.; Matlock, M. D.; Lacey, R. E. Change in ecosystem service values in the San Antonio area, Texas. Ecological Economics, 39, 333-346, 2001. https:// doi.org/10.1016/S0921-8009(01)00250-6

La Notte, A.; D’Amatob, D.; Mäkinenc, H.; Paracchinia, M. L.; Liquetea, C.; Egohd, B.; Genelettif, D.; Crossman, M. D. Ecosystem services classification: A systems ecology 
perspective of the cascade framework. Ecological Indicators, 74, 392-402, 2017. doi: 10.1016/j.ecolind.2016.11.030

Macedo, M. J. H.; Guedes, R. V. S.; Sousa, F. A. Z. Monitoramento e intensidade das secas e chuvas na cidade de Campina Grande/PB. Revista Brasileira de Climatologia, 8, 105-117, 2011. doi: 10.5380/abclima.v8i0.25797

Mansfield, E. Microeconomics: theory and applications. New York: Norton and Company, 5. ed., 1985.

Marengo, J. A.; Torres, R. R.; Alvez, L. M. Drought in Northeast Brazil-past, present, and future. Theoretical and Applied Climatology, 124(3-4), 1189-1200, 2017. doi: 10.1007/s00704-016-1840-8

MEA - Millennium Ecosystem Assessment. Ecosystems and human well-being: biodiversity synthesis. Washington: Island Press, 2005.

Mendoza-González, G.; Martínez, M. L.; Lithgow, D.; Pérez-Maqueo, O.; Simonin, P. Land use change and its effects on the value of ecosystem services along the coast of the Gulf of Mexico. Ecological Economics, 82, 23-32, 2012. doi: 10.1016/j.ecolecon.2012.07.018

Meshesha, D. T.; Tsunekawa, A.; Tsubo, M.; Ali, S. A.; Haregeweyn, N. Land-use change and its socio-environmental impact in Eastern Ethiopia's highland. Regional Environmental Change, 14, 757-768, 2014. doi:10.1007/ s10113-013-0535-2

Munang, R. T.; Thiaw, I.; Rivington, M. Ecosystem Management: Tomorrow's Approach to Enhancing Food Security under a Changing Climate. Sustainability, 3, 937-954, 2011. doi: $10.3390 /$ su3070937

Nelson, E.; Mendoza, G.; Regetz, J.; Polasky, S.; Tallis, H.; Cameron, D. R.; Chan, K. M. A.; Daily, G. C.; Goldstein, J.; Kareiva, P. M.; Lonsdorf, E.; Naidoo, R.; Ricketts, T. H.; Shaw, M. R. Modeling multiple ecosystem services, biodiversity conservation, commodity production and tradeoffs at landscape scales. [Frontiers Ecology Environment, 7, 4-11, 2009. doi: $10.1890 / 080023$

Qaid, A.; Lamit, H. B.; Ossen, D. R.; Shahminan, R. N. R. Urban heat island and thermal comfort conditions at micro-climate scale in a tropical planned city. Energy and Buildin$g s, 133,577-595,2016$. doi: 10.1016/j.enbuild.2016.10.006
Robinson, D.; Jackson, B.; Clothier, B.; Dominati, E.; Marchant, S.; Cooper, D.; Bristow, K. Advances in soil ecosystem services: concepts, models, and applications for earth system life support. Vadose Zone Journal, 12(4), 13p, 2013. doi: 10.2136/vzj2013.01.0027

Santos, H. G. dos; Jacomine, P. K. T.; Anjos, L. H. C. dos.; Oliveira, V. Á. de.; Lumbreras, J. F. Coelho, M. R.; Almeida, J. A. de.; Cunha, T. J. F.; Oliveira, J. B. de. Sistema brasileiro de classificação de solos. Brasília: Embrapa, 3. ed., 2013.

Schneider, A.; Logan, K. E.; Kucharik, C. J. Impacts of urbanisation on ecosystem goods and services in the U.S. Corn Belt. Ecosystems, 15, 519-541, 2012. doi: 10.1007/ s10021-012-9519-1

Solecki, W.; Seto, K. C.; Marcotullio, P. J. It's time for an urbanisation science. Environment Science and Policy for Sustainable Development, 55, 12-17, 2013. doi: 10.1080/00139157.2013.748387

Tolessa, T.; Senbeta, F.; Kidane, M. The impact of land use/land cover change on ecosystem services in the central highlands of Ethiopia. Ecosystem Service, 23, 47-54, 2017. doi: 10.1016/j.ecoser.2016.11.010

USGS - United States Geological Survey. Global Visualization Viewer, 2014. Disponível em: http://glovis.usgs.gov/. Acesso em: set. 2016.

Vieira, R. M. S. P.; Tomasella, J.; Alvala, R. C. S.; Sestini, M. F.; Affonso, A. G.; Rodriguez, D. A.; Barbosa, A. A.; Cunha, A. P. M. A.; Valles, G. F.; Crepani, E.; de Oliveira, S. B. P.; de Souza, M. S. B.; Calil, P. M.; de Carvalho, M. A.; Valeriano, D. M.; Campello, F. C. B.; Santana, M. O. Identifying areas susceptible to desertification in the Brazilian northeast. Solid Earth, 6, 347-360, 2015. doi: 10.5194/ se-6-347-2015

Yi, H.; Güneralp, B.; Filippi, A. M.; Kreuter, U. P.; Güneralp, İ. Impacts of land change on ecosystem services in the San Antonio River Basin, Texas, from 1984 to 2010. Ecological Economics, 135, 125-135, 2017. doi: 10.1016/j. ecolecon.2016.11.019 